\title{
Clinical features and survival analysis of clear cell papillary renal cell carcinoma: A 10-year retrospective study from two institutions
}

\author{
YIQIU WANG ${ }^{1,2^{*}}$, YING DING $^{3 *}$, JIAN WANG $^{4 *}$, MIN GU $^{1}$, ZENGJUN WANG $^{1}$, CHAO QIN $^{1}$,

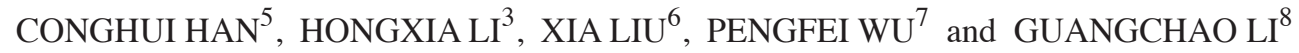

\author{
${ }^{1}$ Department of Urology, The First Affiliated Hospital of Nanjing Medical University, Nanjing, Jiangsu 210029; \\ ${ }^{2}$ Department of Surgical Oncology, The Affiliated Xuzhou Hospital of Medical College of Southeast University, Xuzhou, \\ Jiangsu 221009; Departments of ${ }^{3}$ Pathology and ${ }^{4}$ Oncology, The First Affiliated Hospital of Nanjing Medical University, \\ Nanjing, Jiangsu 210029; Departments of ${ }^{5}$ Urology and ${ }^{6}$ Pathology, The Affiliated Xuzhou Hospital of \\ Medical College of Southeast University, Xuzhou, Jiangsu 221009; ${ }^{7}$ Department of Radiology, \\ The First Affiliated Hospital of Nanjing Medical University, Nanjing, Jiangsu 210029; ${ }^{8}$ Department of Radiology, \\ The Affiliated Xuzhou Hospital of Medical College of Southeast University, Xuzhou, Jiangsu 221009, P.R. China
}

Received November 29, 2017; Accepted May 15, 2018

DOI: $10.3892 / \mathrm{ol} .2018 .8752$

\begin{abstract}
Clear cell papillary renal cell carcinoma (CCPRCC) is a recently recognized subtype of renal cell carcinoma entity, however, little is known about its clinical features. In the present study, 26 cases of CCPRCC were screened out from two institutions. The patient data, tissue pathology, immunohistochemical phenotype, computed tomographic images and survival analysis were studied. The mean age was 53.3 years and the average tumor size was $2.5 \mathrm{~cm}$. A total of 17 patients' body mass indexes were higher than the normal level. A total of 11 patients had hypertension and 6 patients had a smoking history. Histopathologically, all cases of CCPRCC exhibited
\end{abstract}

Correspondence to: Dr Min Gu, Department of Urology, The First Affiliated Hospital of Nanjing Medical University, 300 Guangzhou Road, Nanjing, Jiangsu 210029, P.R. China

E-mail: lancetgu@sina.com

${ }^{*}$ Contributed equally

Abbreviations: CCPRCC, clear cell papillary renal cell carcinoma; CCRCC, clear cell renal cell carcinoma; PRCC, papillary renal cell carcinoma; ESRD, end-stage renal disease; RCC, renal cell carcinoma; ISUP, International Society of Urological Pathology; WHO, World Health Organization; CRCC, chromophobe renal cell carcinoma; CT, computed tomography; Ki67 LI, Ki67 labeling index; CMP, corticomedullary phase; NP, nephrographic phase; EP, excretory phase; ROI, region of interest; CSS, cancer-specific survival; PFS, progression-free survival; SD, standard deviation; MRC, multilocular renal cyst; BMI, body mass index; RN, radical nephrectomy; PN, partial nephrectomy; HIFs, hypoxia-inducible factors

Key words: clear cell papillary renal cell carcinoma, clinical features, survival analysis a tubular and papillary architecture, small to medium-sized cuboidal tumor cells with clear cytoplasms, and a low Fuhrman nuclear grade. All tumors were encapsulated by variably thick fibrous capsules. Immunohistochemistry showed diffuse and moderate to strong cytoplasmic staining for CK7, CA IX and vimentin, but negative for AMACR and CD10 (sometimes focally positive) in all cases. According to the results of Ki67 labeling index, the expression of Ki67 in CCPRCC was much lower than that in clear cell renal cell carcinoma (CCRCC) ( 2.19 vs. $7.07 \%, \mathrm{P}<0.001)$ and that in papillary renal cell carcinoma (PRCC) (2.19 vs. $6.65 \%, \mathrm{P}<0.001)$. Radiographically, the tumors were shown as small masses with smooth contour and mixed enhancement pattern. The multiphasic attenuation curve for CCPRCC, like that for CCRCC, increased in the corticomedullary phase markedly and decreased in the nephrographic phase and excretory phase gradually. At a median follow-up period of 50 months, no cancer-specific death or tumor recurrence was observed. Considering the favorable prognosis of CCPRCC, preoperative biopsy in order to make clear the diagnosis is particularly important. In light of the present findings, partial nephrectomy for patients with CCPRCC is recommended. If the patients cannot tolerate surgery, closed monitoring or radiofrequency ablation may be considered.

\section{Introduction}

Clear cell papillary renal cell carcinoma (CCPRCC) was initially described by Tickoo et al in 2006 as a subtype of renal tumor of patients with end-stage renal disease (ESRD) (1). Subsequently, it has been shown that CCPRCC may also occur in healthy and functional kidneys as well (2-4). In 2013, CCPRCC was included as a subtype of renal cell carcinoma (RCC) in the International Society of Urological Pathology (ISUP) Vancouver Classification of Renal Neoplasia (5). Formally published during the spring of 2016, the new version of World Health Organization (WHO) Classification of Tumors of the Urinary System and Male Genital Organs described some 
new entities, including CCPRCC and 5 other new subtypes of RCC (6).

Up to now, $>400$ patients with CCPRCC have been reported (1-4,7-26). By analyzing the published cases, this tumor is estimated to account for $1-5 \%$ of all renal epithelial neoplasms $(5-10,15,18)$, which makes CCPRCC the fourth most common RCC (7), just next to clear cell renal cell carcinoma (CCRCC), papillary renal cell carcinoma (PRCC), and chromophobe renal cell carcinoma (CRCC). Despite some overlapping features, CCPRCC is known to be morphologically, immunohistochemically, and genetically distinct from both CCRCC and PRCC (27). However, none of urologists or oncologists has studied this new type of RCC from the view of clinical diagnosis and treatment. Little is known about whether CCPRCC has relatively specific characteristics of clinical epidemiology, clinical laboratory and radiology. Furthermore, CCPRCC may present often as small masses and its incidence is as high as $1 / 15$ in RCC of low stage (pT1aNOM0) and low Fuhrman nuclear grade (1 and 2) (15). Whether the prognosis of CCPRCC is different from other RCC subtypes is crucial for treatment of early-stage RCC. Therefore, the purpose of this study was to (1) determine clinical features and survival analysis of CCPRCC (2) evaluate similarities and differences with CCRCC and PRCC to better understand the biologic characteristic of this newly recognized entity (3) review its histological morphology and immunohistochemical expression for correct classification.

\section{Materials and methods}

Case selection and clinical data review. From 2006 to 2015, among the 1,519 RCC patients who visited the two hospitals (the First Affiliated Hospital of Nanjing Medical University and the Affiliated Xuzhou Hospital of Medical College of Southeast University), 26 cases of CCPRCC were identified and reviewed by three pathologists (Ding, Li and Liu). The flow diagram explaining patient selection is shown in Fig. 1. Patient data, including age, sex, height, weight, primary diagnosis, past medical history, preoperative examination results (including routine blood test, urinalysis, blood biochemical tests and serum tumor markers) and tumor characteristics were obtained from the medical records. Body mass index (BMI) was calculated as the weight in kilograms divided by the height in meter squared. Commonly accepted BMI ranges in Chinese people are normal weight $\left(18.5-23.9 \mathrm{~kg} / \mathrm{m}^{2}\right)$, overweight $\left(24-27.9 \mathrm{~kg} / \mathrm{m}^{2}\right)$ and obesity (over $28 \mathrm{~kg} / \mathrm{m}^{2}$ ).

Meanwhile, among the cases of RCC with preoperative multiphasic computed tomography (CT) images data, we randomly selected 30 cases of CCRCC and PRCC respectively, and their pathological stages were consistent with CCPRCC (pT1N0M0). We also collected these patients' information. All patients signed the informed consent and the research was approved by the Ethics Committee of the First Affiliated Hospital of Nanjing Medical University (Ethical approval number: 2016-SRFA-011) and the Ethics Committee of the Affiliated Xuzhou Hospital of Medical College of Southeast University (Ethical approval no. XZXY-LJ-20160111-008).

Immunohistochemistry. Specimens, including 26 CCPRCC, $30 \mathrm{CCRCC}$ and $30 \mathrm{PRCC}$, were fixed in formalin and embedded in paraffin. The $4-\mu \mathrm{m}$ thick sections were stained with the following panel of markers: CK7 (OV-TL 12/30, 1:200; Dako, Carpinteria, CA, USA); CD10 (56C6, 1:25; Novocastra, Newcastle upon Tyne, UK); AMACR (13H4, ready-to-use; Dako); CA IX (TH22, 1:100; Novocastra, Buffalo Grove, IL, USA); vimentin (Vim 3B4, 1:250); Ki67 (MIB-1, 1:200) (both from Dako, Glostrup, Denmark). Immunoreaction was performed with an automated immunostainer from Ventana (Ventana Medical Systems, Tucson, AZ, USA). The immunohistochemistry results (CK7, C10, AMACR, CA IX and RCC maker) were interpreted as negative, weak $(<30 \%$ staining), moderate (30-70\% staining) and strong (>70\% staining). Ki67 positive cells showed stained brownish-yellow granules in the nucleus. According to the literature written by Delahunt et al (28), the area with the highest fraction of Ki67-stained cells in section was chosen at a X10 objective magnification, then it was examined at X400 objective magnification. Finally, Ki67 labeling index (Ki67 LI) was made through counting 1,000 cancer cells (percentage of nuclei showing positive staining).

CT examination and image analysis. All multidetector CT examinations were performed by either 16 detector row helical scanners (Optima CT520) (the First Affiliated Hospital of Nanjing Medical University) or 64 detector row helical scanners (Discovery CT750 HD) (both from General Electric Medical Systems, Milwaukee, WI, USA) (the Affiliated Xuzhou Hospital of Medical College of Southeast University). For the acquisition of all images, scans were obtained with the following parameters: A craniocaudal direction with gantry tilt 0 degrees, a scan time of $0.8 \mathrm{sec}, 120 \mathrm{kVp}$, variable tube current and a section thickness interval of 2.5-5 mm depending on the protocol used.

All patients with CCRCC (30 cases) and PRCC (30 cases) underwent four-phase helical renal CT scanning, including unenhanced phase, corticomedullary phase (CMP), nephrographic phase (NP) and excretory phase (EP). Among the 25 patients with CCPRCC (excluding 1 patient with ESRD), 10 underwent four-phase scanning, 4 underwent three-phase (unenhanced phase, CMP and NP) scanning, 4 only underwent unenhanced phase scanning and 7 patients did not undergo CT. During the four-phase studies, $80-100 \mathrm{ml}$ contrast medium (nonionic iohexol concentration $300 \mathrm{mgI} / \mathrm{ml}$ ) (Omnipaque; GE Healthcare, Logan, UT, USA) was injected intravenously into the antecubital vein at a rate of $3.0 \mathrm{ml} / \mathrm{sec}$ after an unenhanced helical CT was obtained. Scanning for the CMP, NP and EP was in 30, 90 and $300 \mathrm{sec}$ after contrast injection, respectively. For three-phase studies, time-delay images were obtained at varied combinations of corticomedullary and nephrographic phases.

Two experienced abdominal radiologists ( $\mathrm{Wu}$ and $\mathrm{Li}$ ), who were blinded to renal cell carcinoma subtypes, reviewed the CT images and evaluated the tumor size, enhancement pattern, calcification, and tumor contour were independently. They measured the attenuation values of renal lesions with the observer-defined region of interest (ROI) at a size of $\sim 0.5-1 \mathrm{~cm}^{2}$. The radiologists kept two ROIs in the center of the tumor lesion or the most homogenously enhanced part of the lesion, which were consistent in location during all CT phases. Then the mean of these 2 values was calculated and the measurement was reviewed by two radiologists ( $\mathrm{Wu}$ and $\mathrm{Li}$ ). 


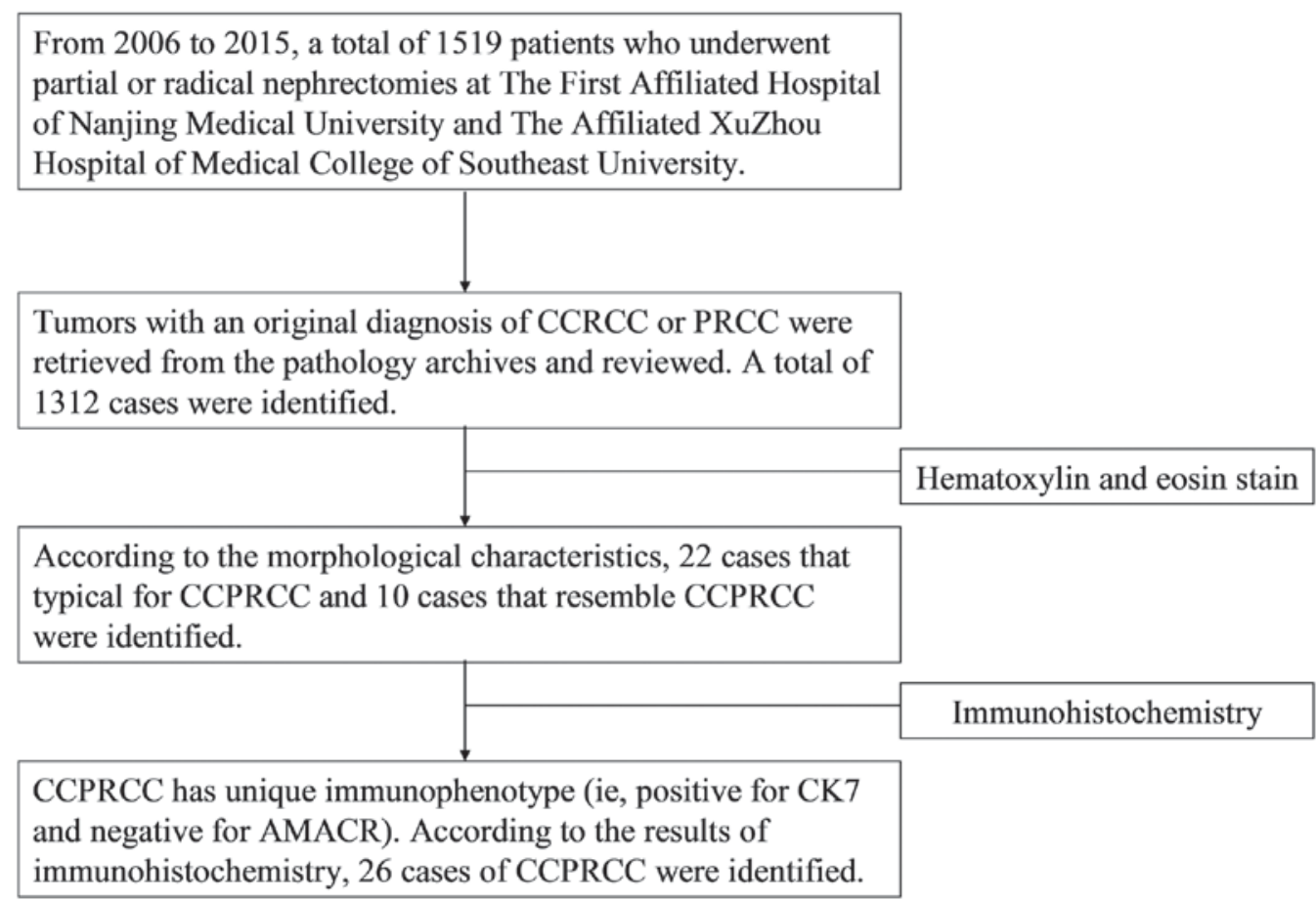

Figure 1. Flow diagram explaining patient selection.

In addition, the attenuation value of the aorta was measured as a control in each phase.

Follow-up and evaluation. According to the 2010 TNM staging system and the Fuhrman grade classification, a total of 955 patients diagnosed with low stage (pT1N0M0) and low nuclear grade (1 and 2) RCC were included in this study. We recorded patients' information, including age, sex, surgical method, pathologic feature and follow-up data. After excluding the patients with unilateral multiple RCC tumors, bilateral RCC tumors, other types of malignant tumors and no follow-up data, 563 patients with CCRCC, 82 patients with PRCC and 25 patients with CCPRCC were selected. All the patients received follow-up evaluations every 3 months in the first year and then twice a year. They received physical examinations, laboratory tests, and imaging tests (chest X-ray, ultrasonography or CT when necessary) and were evaluated carefully by urologists and radiologists. If the patients died, the causes of death were retrieved from the patients' family members or hospital records. The duration of follow-up was calculated from the date of the operation to the date of death or last follow-up before June 2016. Then cancer-specific survival (CSS) and progression-free survival (PFS) were estimated.

Statistical analysis. All the statistical analyses were performed with SAS 9.3 (SAS institute Inc., Cary, NC, USA). The results were presented as means \pm standard deviation (SD). The measurement data (such as age, size of tumor and the expression profiles of Ki67) were compared using the Kruskal-Wallis test and the data of rate or constituent ratio (such as patient sex, enhancement pattern, tumor contour and calcification in the CT image) were compared using the Chi-square test. We performed independent-samples $t$ test to compare the attenuation values of CCPRCC with those of CCRCC and PRCC in four phases (unenhanced phase, CMP, nephrographic phase and EP). T-tests were also performed to test the magnitude of aortic attenuation among the four groups in each phase. CSS and PFS were estimated with the Kaplan-Meier method and were compared with the log-rank test. Univariate and multivariate Cox regression models were used to define the risk factors for tumor recurrence and patient death. Levels of statistical significance were fixed for P-values $<0.05$.

\section{Results}

Clinical features. A total of 26 patients were diagnosed with CCPRCC in this study, accounting for $1.7 \%$ of all renal cell carcinomas (26/1519). The clinical features of the patients are summarized in Table I. The mean age of patients at diagnosis was $53.3 \pm 12.3$ years (range $36-74$ years), and the mean tumor size was $2.5 \pm 1.5 \mathrm{~cm}$ (range 0.5 to $6.5 \mathrm{~cm}$ ). The fact that 19 patients were male and 7 were female indicates a male preference. In addition, 18 patients' tumors were located on the left side and 8 on the right side. There were 4 patients with multilocular renal cyst (MRC), 1 with ESRD, 1 with renal calculus and 1 with bilateral renal tumors (the right side was CCPRCC and the left side was CCRCC). We also found that most of the patients with abnormal BMI (17/26, 65.4\%), including 2 obese patients. In terms of clinical symptoms, most of the patients were found to have tumors by chance when they were examined in medical centers, and only 8 of 26 patients had flank pain, abdominal pain or hematuria. Some patients have comorbidities, such as hypertension $(11 / 26,42.3 \%)$, diabetic mellitus $(3 / 26,11.5 \%)$, benign prostatic hyperplasia $(3 / 26,11.5 \%)$, atherosclerotic cerebral infarction $(2 / 26,7.7 \%)$, coronary heart disease $(1 / 26,3.8 \%)$, fatty liver $(1 / 26,3.8 \%)$ and pulmonary tuberculosis $(1 / 26,3.8 \%)$. Six patients had a smoking history (20 cigarettes per day on average) and 

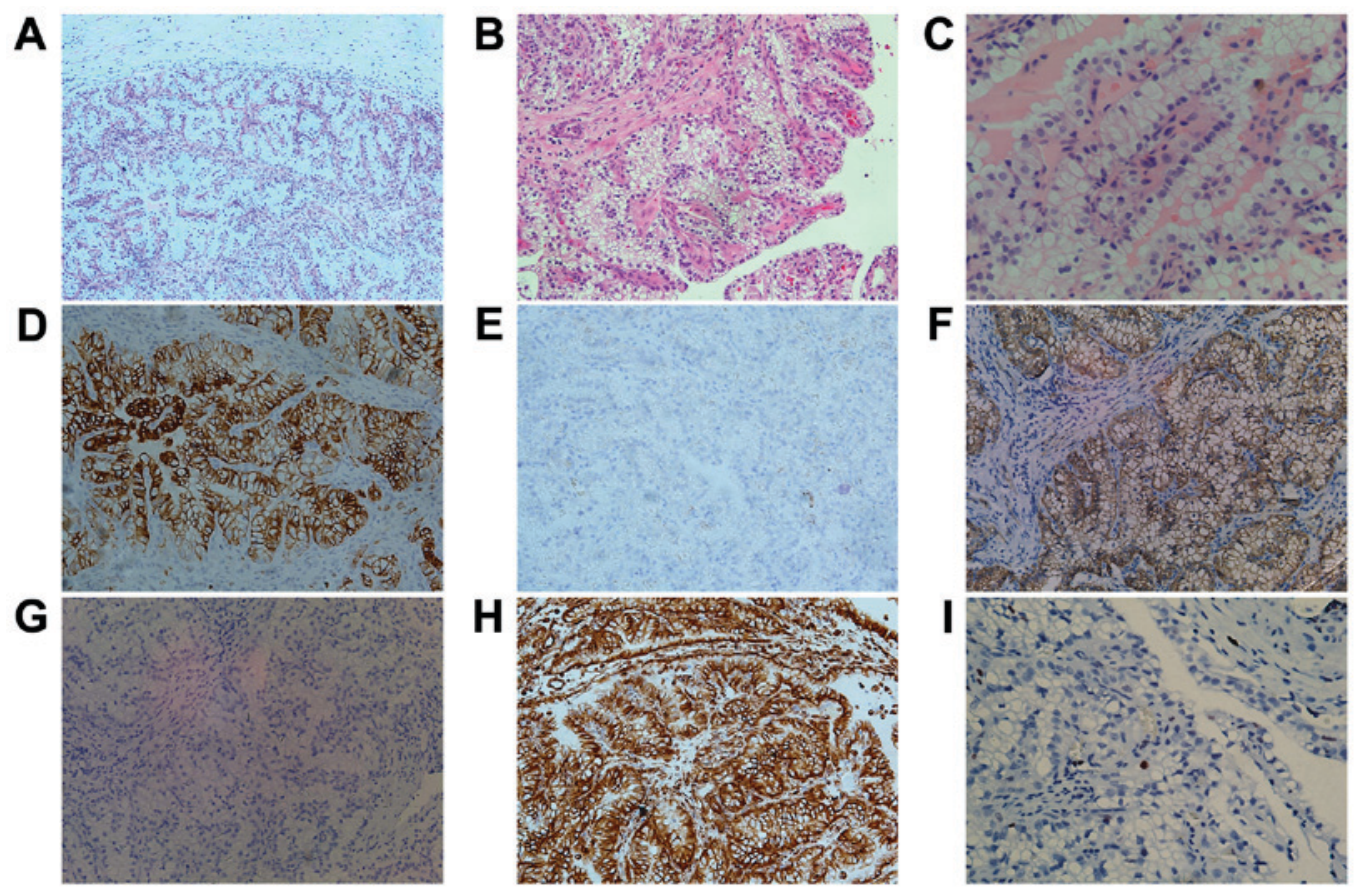

Figure 2. Histomorphological and immunohistochemical features of CCPRCC. (A) The tumor is predominantly papillary encapsulated by a fibrous capsule (magnification, x100). (B) The papillae are small and delicate and are covered by cells with abundant clear cytoplasm (magnification, $\mathrm{x} 200)$. (C) The low-grade nuclei located in the luminal side of the tumor cells (magnification, x400). (D) CK7 staining shows diffuse strong positive (magnification, x200). (E) The expression of AMACR is negative (magnification, x200). (F) CA IX staining shows 'cup-like' positive with absence of apical staining (magnification, x200). (G) CD10 is negative in tumor cells (magnification, $\mathrm{x} 200$ ). (H) Vimentin staining also shows strong positive (magnification, $\mathrm{x} 200$ ). (I) A few tumor cells stained brownish-yellow granules in the nucleus exhibit positive for Ki67 staining (magnification, x400). CCPRCC, clear cell papillary renal cell carcinoma.
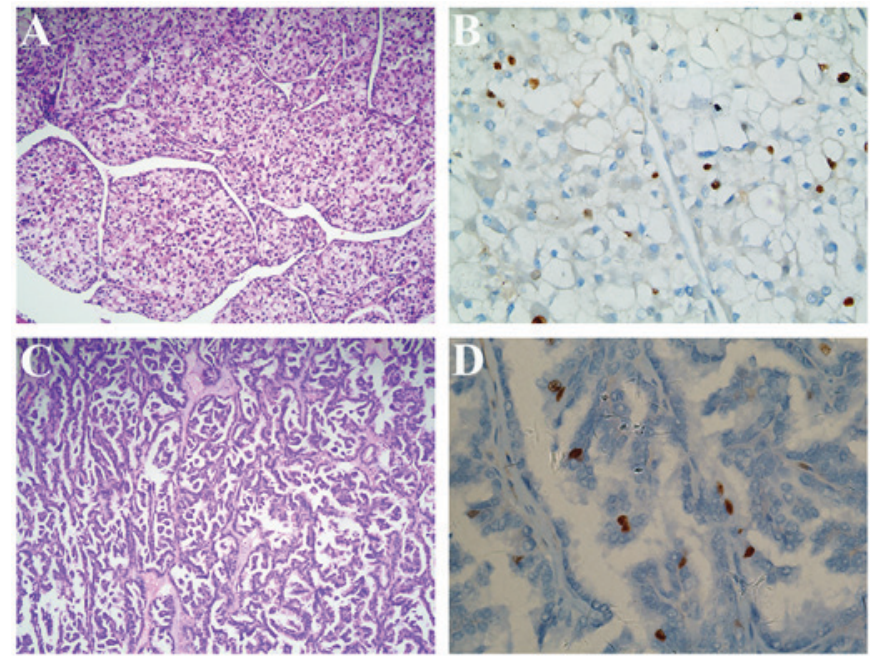

Figure 3. The features of histomorphology and immunohistochemical staining of Ki67 in the tumor of CCRCC and PRCC. (A) The reticular structure of CCRCC consists of clear cells, separated by blood vessels with thin vessel wall (magnification, x100). (B) Ki67-stained cells in the tumor of CCRCC (magnification, x400). (C) Typical papillary structure arranged by small tumor cells in PRCC (magnification, x100). (D) Ki67-stained cells in the tumor of PRCC (magnification, x400). CCRCC, clear cell renal cell carcinoma; PRCC, papillary renal cell carcinoma.

2 had a drinking history (1 kg liquor per month on average). Eleven patients received radical nephrectomy (RN) and 15 received partial nephrectomy (PN).

We also analyzed the results of laboratory tests, including blood routine, urine routine, blood biochemical and serum tumor markers. No abnormalities were observed except for high serum uric acid in 6 patients, mild abnormal glutamic-pyruvic transaminase in 2 patients and positive urine red blood cell in 1 patient.

Pathologic features. Histopathologically, all tumors were encapsulated by variably thick fibrous capsules and limited to the renal parenchyma. Composed of different proportions of papillary, tubular, cystic, acinar and nested architectures, these tumors showed several morphologic patterns. The papillae, covered by small to medium-sized cuboidal cells with abundant clear cytoplasm, were mostly small, delicate and enclosed in cysts, and occasionally showed secondary and tertiary hierarchical branching. No calcification, necrosis or hemosiderin was present in these cases. All tumors was either Fuhrman nuclear grade $1(8 / 26,30.8 \%)$ or grade $2(18 / 26,69.2 \%)$. In most of these tumors, a characteristic nuclear horizontally linear arrangement away from the basement membrane was identified. The representative microscopic illustrations of CCPRCC are shown in Fig. 2A-C. In addition, neither fat invasion nor renal vein thrombosis was observed and all cases were stage I. Histomorphological features of CCRCC and PRCC are shown in Fig. 3A and C, respectively.

Immunohistochemically, we assessed the profile of CK7, AMACR, CA IX, CD10, vimentin and Ki67 in the 26 CCPRCC cases. All cases were diffusely and moderate to strong cytoplasmic staining for CK7 (Fig. 2D), CA IX (Fig. 2F) and vimentin (Fig. 2H), but negative for AMACR (Fig. 1E). The CD10 was negative or focally positive in tumor cells (Fig. 2G). The immunohistochemical staining of Ki67 in different subtypes of renal cell carcinoma are respectively shown in Figs. 2I, 3B and D. According to the results of Ki67 LI, the 


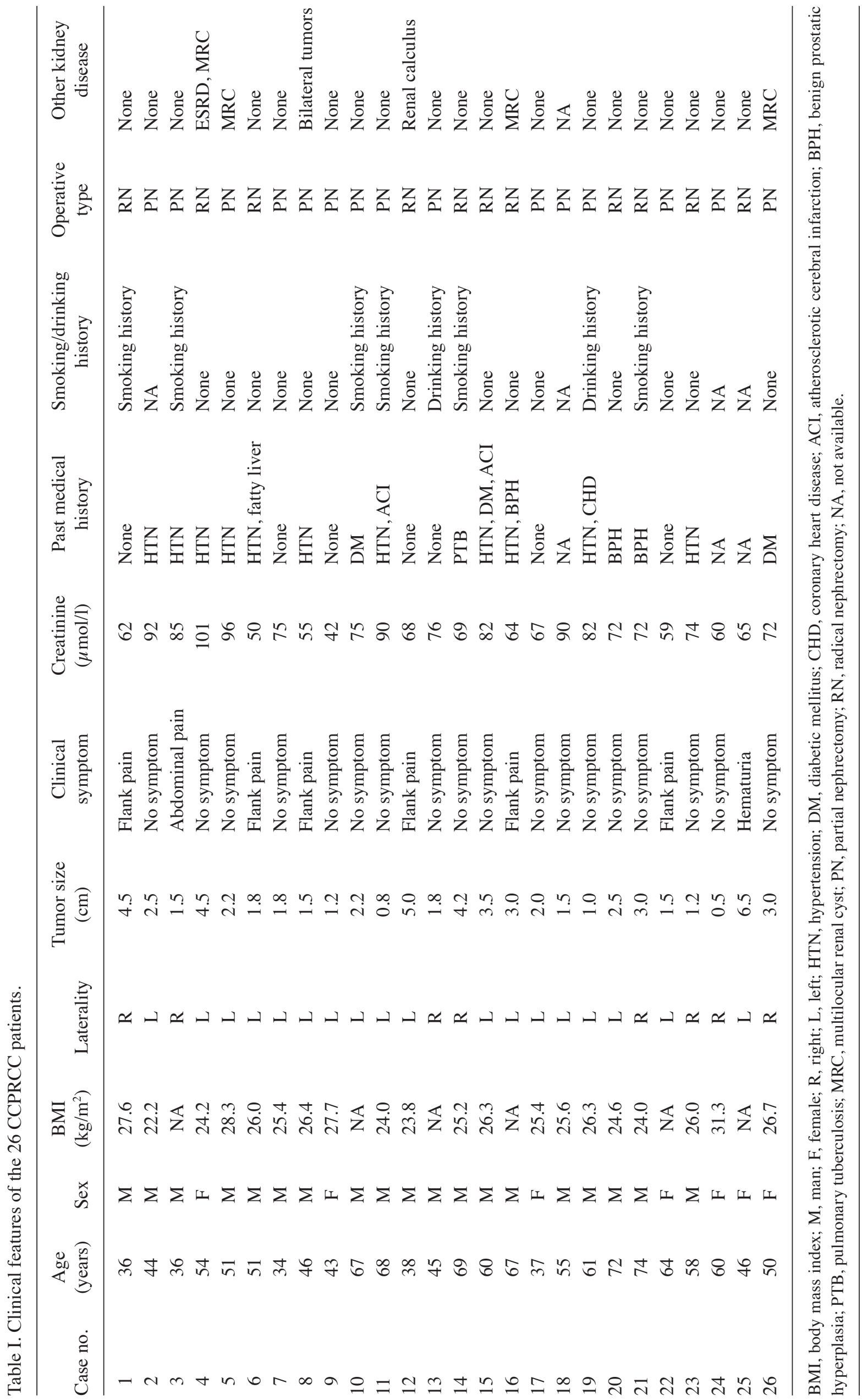


Table II. Imaging characteristics of patients and renal lesions.

\begin{tabular}{|c|c|c|c|c|}
\hline Feature & $\operatorname{CCPRCC}(n=14)$ & $\operatorname{CCRCC}(n=30)$ & $\operatorname{PRCC}(n=30)$ & P-value \\
\hline Age (year) & $51.3 \pm 13.4$ & $54.5 \pm 10.7$ & $58.6 \pm 11.1$ & 0.154 \\
\hline Lesion size $(\mathrm{cm})$ & $2.4 \pm 1.2$ & $3.1 \pm 0.9$ & $2.9 \pm 1.0$ & 0.086 \\
\hline \multicolumn{5}{|c|}{ Enhancemen pattern $(\%)$} \\
\hline Homogeneous & $4(28.6)$ & $9(30.0)$ & $22(73.3)$ & 0.001 \\
\hline Heterogeneous & $10(71.4)$ & $21(70.0)$ & $8(26.7)$ & \\
\hline \multicolumn{5}{|l|}{ Tumor contour (\%) } \\
\hline Smooth & $14(100)$ & $15(50.0)$ & $27(90.0)$ & $<0.0001$ \\
\hline Other & 0 & $15(50.0)$ & $3(10.0)$ & \\
\hline Calcification (\%) & 0 & $1(6.7)$ & $1(6.7)$ & 0.787 \\
\hline
\end{tabular}

CCPRCC, clear cell papillary renal cell carcinoma; CCRCC, clear cell renal cell carcinoma; PRCC, papillary renal cell carcinoma.

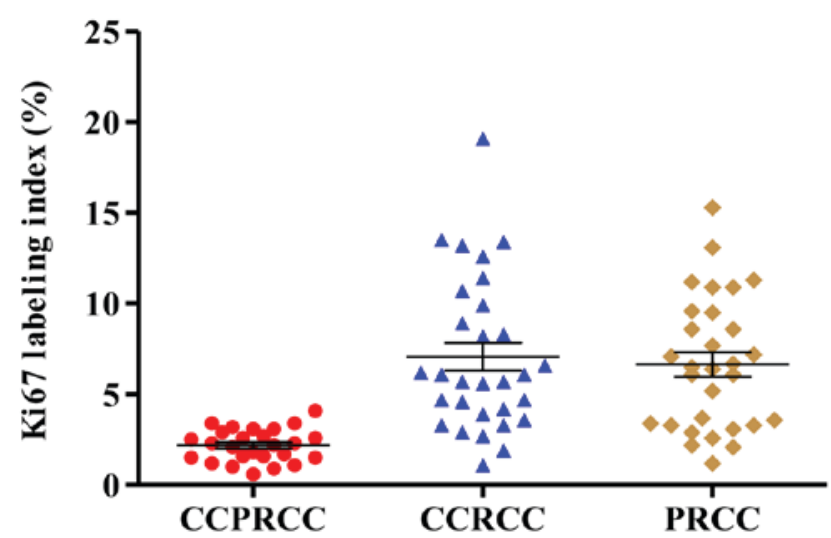

Figure 4. Expression of Ki67 in different subtypes of renal cell carcinoma. CCPRCC, clear cell papillary renal cell carcinoma; CCRCC, clear cell renal cell carcinoma; PRCC, papillary renal cell carcinoma.
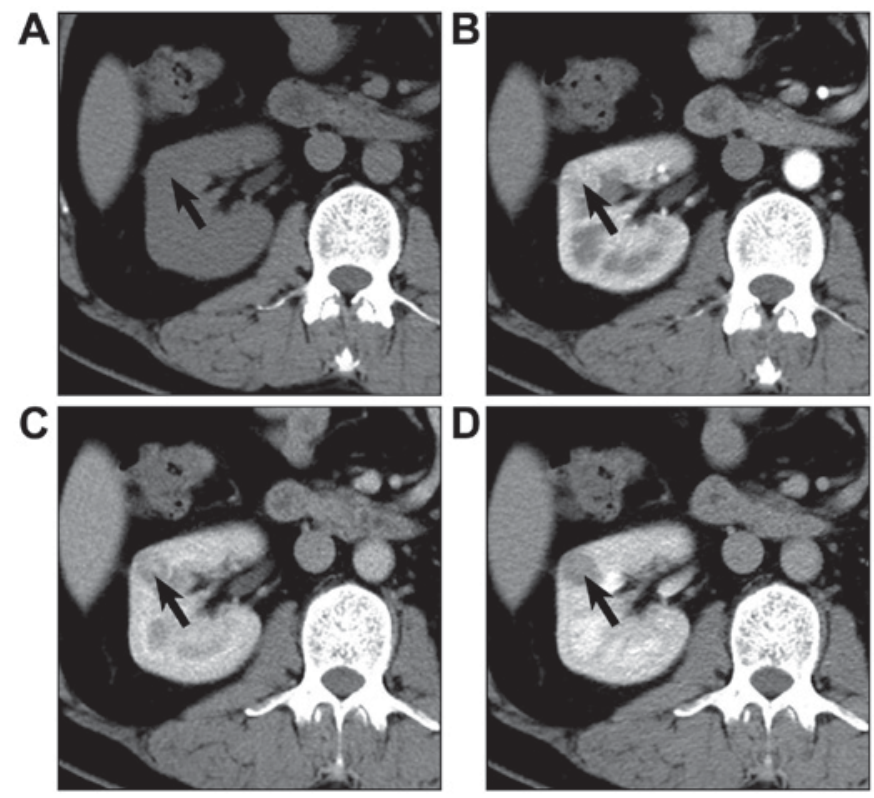

Figure 5. Multiphasic enhancement at axial multidetector CT in a 36-year-old man with CCPRCC. Arrow points at the kidney tumor. (A) Unenhanced phase. (B) Corticomedullary phase. (C) Nephrographic phase. (D) Excretory phase. CCPRCC, clear cell papillary renal cell carcinoma.

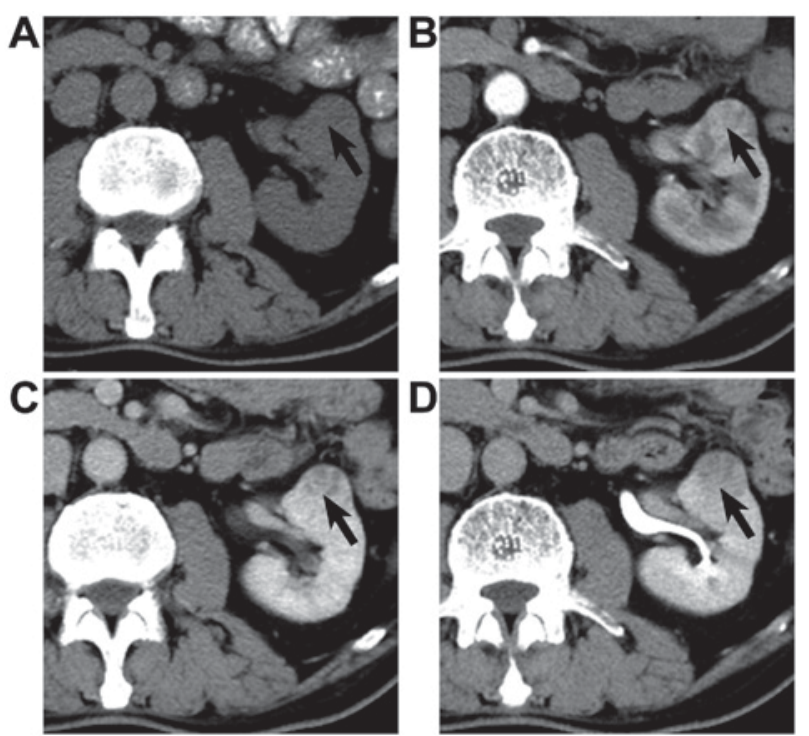

Figure 6. Multiphasic enhancement at axial multidetector CT in a 67-yearold man with CCRCC. Arrow points at the kidney tumor. (A) Unenhanced phase. (B) Corticomedullary phase. (C) Nephrographic phase. (D) Excretory phase. CCRCC, clear cell renal cell carcinoma.

expression of Ki67 in CCPRCC was much lower than that in CCRCC (2.19 vs. 7.07\%, P<0.001; Fig. 4) and that in PRCC (2.19 vs. $6.65 \%, \mathrm{P}<0.001$; Fig. 4). However, although the expression of Ki67 in CCRCC was still higher than that in PRCC (7.07 vs. $6.65 \%, \mathrm{P}=0.848$; Fig. 4), the difference was not significant.

CT features. Major CT findings and characteristics for each of the groups are presented in Table II. The mean lesion size was $2.4 \pm 1.4 \mathrm{~cm}$ for CCPRCC, $3.1 \pm 0.9 \mathrm{~cm}$ for CCRCC and $2.9 \pm 1.0 \mathrm{~cm}$ for PRCC $(\mathrm{P}=0.086)$. There were statistically significant differences in the enhancement patterns among all subtypes $(\mathrm{P}=0.001)$, most CCPRCC $(10 / 14,71.4 \%)$ and CCRCC $(21 / 30,70.0 \%)$ cases had a mixed enhancement pattern while PRCC commonly had a homogeneous enhancement pattern $(22 / 30,73.3 \%)$. In terms of tumor contour, the proportion of smooth tumor in CCPRCC was higher than that in CCRCC (100 vs. 50.0\%, $\mathrm{P}=0.001)$ and that in PRCC (100 vs. $90.0 \%$, $\mathrm{P}=0.220$ ). Calcification within the tumor was noted in 1 patient 


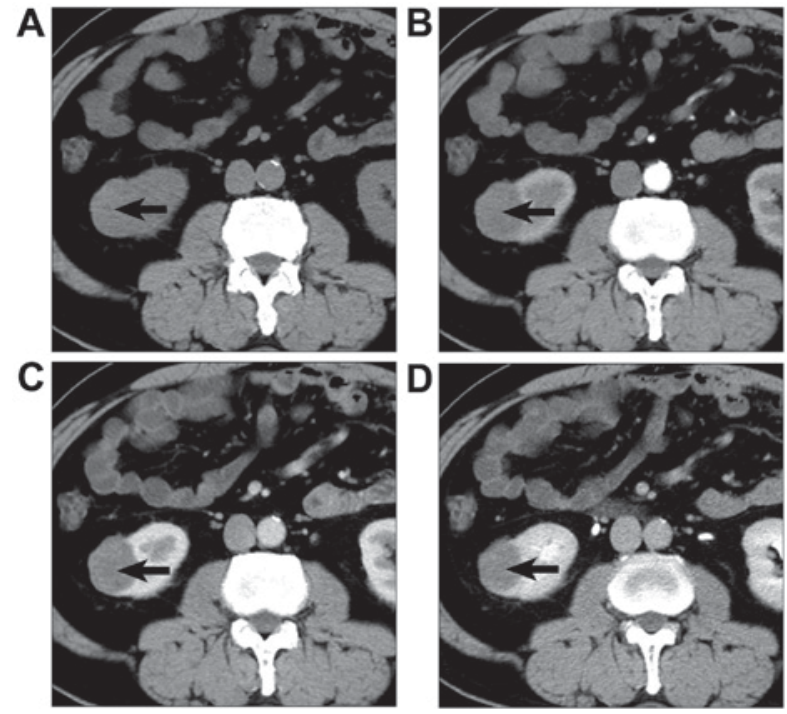

Figure 7. Multiphasic enhancement at axial multidetector CT in a 57-year-old man with PRCC. Arrow points at the kidney tumor. (A) Unenhanced phase. (B) Corticomedullary phase. (C) Nephrographic phase. (D) Excretory phase. PRCC, papillary renal cell carcinoma.

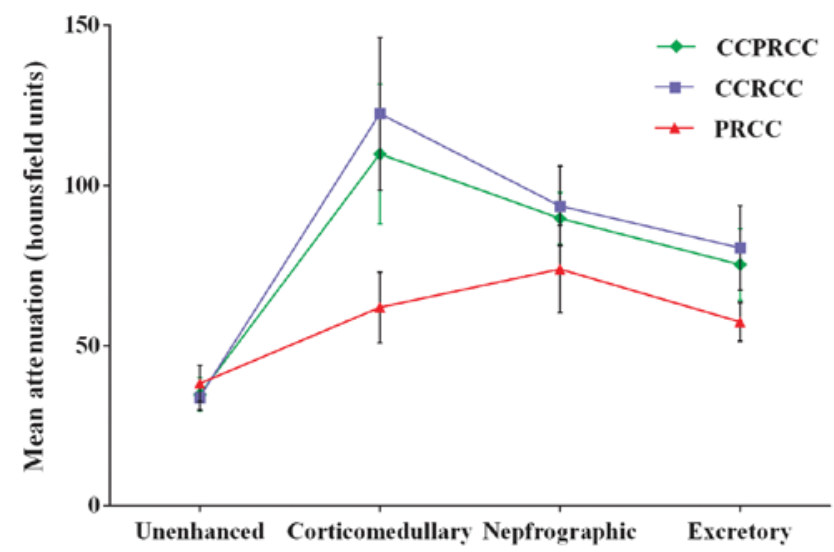

Figure 8. Multiphasic attenuation curves for CCPRCC, CCPRCC, and PRCC Data points are mean attenuation for each phase. Error bars, $95 \%$ confidence intervals for the mean. CCPRCC, clear cell papillary renal cell carcinoma; PRCC, papillary renal cell carcinoma; CCRCC, clear cell renal cell carcinoma.

(6.7\%) with CCRCC, in 1 patient (6.7\%) with PRCC, and none in patients with CCPRCC. These differences, however, were not significant $(\mathrm{P}>0.05)$.

Typical lesions from each group are presented in Figs. 5-7. Mean attenuation values for CCPRCC, CCRCC, and PRCC in each phase are shown in Table III and Fig. 8. The mean pre-enhancement attenuation values of all 3 subtypes did not differ from each other. Although the magnitude of CCRCC enhancement was greater than that of CCPRCC in CMP (122.4 HU vs. 109.8 HU), NP (93.6 HU vs. 89.7 HU) and EP (80.5 HU vs. $75.3 \mathrm{HU}$ ), all these differences were not significant $(\mathrm{P}>0.05)$. Different from mean enhancement of these 2 subtypes of RCC peaked in the CMP, the peak height of enhancement for PRCC was in the NP. However, the magnitude of enhancement of PRCC was significantly lower than that of CCPRCC in the CMP (61.9 HU vs. 109.8 HU, $\mathrm{P}=0.009)$, NP (73.9 HU vs. 89.7 HU, P=0.038), and EP (57.4 HU vs. 75.3 HU, $\mathrm{P}=0.028$ ). Comparing the CCPRCC group with the
Table III. Attenuation of renal lesions on the basis of histologic subtype.

\begin{tabular}{lccc}
\hline Imaging phase & CCPRCC & CCRCC & PRCC \\
\hline Lesion attenuation & & & \\
Unenhanced & $34.8 \pm 5.2$ & $33.9 \pm 3.9$ & $38.2 \pm 5.7$ \\
P-value & - & 0.596 & 0.418 \\
Corticomedullary & $109.8 \pm 21.8$ & $122.4 \pm 23.8$ & $61.9 \pm 11.0$ \\
P-value & - & 0.675 & 0.009 \\
Nephrographic & $89.7 \pm 8.1$ & $93.6 \pm 12.4$ & $73.9 \pm 13.6$ \\
P-value & - & 0.422 & 0.038 \\
Excretory & $75.3 \pm 11.2$ & $80.5 \pm 13.2$ & $57.4 \pm 6.0$ \\
P-value & - & 0.508 & 0.028 \\
Aortic attenuation & & & \\
Unenhanced & $44.7 \pm 3.0$ & $43.7 \pm 3.3$ & $44.2 \pm 3.6$ \\
P-value & - & 0.581 & 0.895 \\
Corticomedullary & $221.3 \pm 37.8$ & $227.2 \pm 27.4$ & $236.8 \pm 29.8$ \\
P-value & - & 0.314 & 0.437 \\
Nephrographic & $126.5 \pm 14.1$ & $119.7 \pm 13.4$ & $123.8 \pm 11.6$ \\
P-value & - & 0.848 & 0.353 \\
Excretory & $94.9 \pm 8.1$ & $91.5 \pm 7.68$ & $91.5 \pm 7.2$ \\
P-value & - & 0.880 & 0.938 \\
\hline CCRCC & & & \\
\hline
\end{tabular}

CCPRCC, clear cell papillary renal cell carcinoma; CCRCC, clear cell renal cell carcinoma; PRCC, papillary renal cell carcinoma.

CCRCC and PRCC groups, there were no significant differences in aortic attenuation in any of the phases.

Survival analysis. The patients' clinical and pathological characteristics are listed in Table IV by histologic subtype. The median follow-up among the patients with CCPRCC, CCRCC, and PRCC was 50, 57 and 51.5 months, respectively. None of the 25 patients with CCPRCC died of the disease or demonstrated disease progression. Among the 563 patients with CCRCC, 46 died due to the disease and 59 were observed to have tumor recurrence. The PFS rate was $89.5 \%$ and the CSS rate was $91.8 \%$ at 10 years. Meanwhile, in all 82 patients with PRCC, 3 patients died of it and 5 patients had tumor recurrence. The PFS rate was $93.9 \%$ and the CSS rate was $96.3 \%$ at 10 years. Although the results suggested that the prognosis of CCPRCC was better than that in the other two groups, the Kaplan-Meier curves did not show significant differences in either the CSS $(\mathrm{P}=0.195$, log-rank test) or PFS rates $(\mathrm{P}=0.182$, log-rank test $)$ for the three subtypes (Figs. 9 and 10).

Among all the investigated prognostic factors, tumor size $(\mathrm{P}<0.0001, \mathrm{HR}=6.16)$, Fuhrman's nuclear grade $(\mathrm{P}=0.01$, $\mathrm{HR}=3.29)$, and operative type $(\mathrm{P}=0.02, \mathrm{HR}=2.84)$ had a significant impact on tumor recurrence in the univariate analysis. Multivariate analysis subsequently showed that only tumor size $(\mathrm{P}<0.0001, \mathrm{HR}=6.22)$, as an independent factor, had an impact on tumor recurrence (Table V). Both univariate analysis and multivariate analysis could not detect the results of RCC subtype because the sample numbers were not balanced in the 3 groups and CCPRCC accounted for a rather small 
Table IV. Clinical and pathologic characteristics of follow-up patients.

\begin{tabular}{|c|c|c|c|}
\hline Characteristic & $\operatorname{CCPRCC}(\mathrm{n}=25)$ & $\operatorname{CCRCC}(n=563)$ & $\operatorname{PRCC}(n=82)$ \\
\hline \multicolumn{4}{|l|}{ Age (month) } \\
\hline Mean $\pm \mathrm{SD}$ & $53.6 \pm 13.4$ & $56.7 \pm 12.3$ & $58.3 \pm 13.9$ \\
\hline Range & $34-74$ & $20-86$ & $20-83$ \\
\hline \multicolumn{4}{|l|}{$\operatorname{Sex}(\%)$} \\
\hline Male & $18(72.0)$ & $361(64.1)$ & $68(82.9)$ \\
\hline Female & $7(28.0)$ & $202(35.9)$ & $14(17.1)$ \\
\hline \multicolumn{4}{|c|}{ Tumor size (cm) } \\
\hline Mean \pm SD & $2.5 \pm 1.5$ & $4.1 \pm 1.7$ & $3.7 \pm 1.6$ \\
\hline Range & $0.5-6.5$ & $1.0-7.0$ & $0.5-7.0$ \\
\hline \multicolumn{4}{|c|}{ Nuclear grade $(\%)$} \\
\hline 1 & $9(36.0)$ & $123(21.8)$ & $15(18.3)$ \\
\hline 2 & $16(64.0)$ & $440(78.2)$ & $67(81.7)$ \\
\hline \multicolumn{4}{|c|}{ Operative type (\%) } \\
\hline $\mathrm{PN}$ & $14(56.0)$ & $99(17.6)$ & $26(31.7)$ \\
\hline $\mathrm{RN}$ & $11(44.0)$ & $464(82.4)$ & $56(68.3)$ \\
\hline \multicolumn{4}{|c|}{ Follow-up time (month) } \\
\hline Mean \pm SD & $57.3 \pm 33.2$ & $57.8 \pm 24.0$ & $53.5 \pm 24.8$ \\
\hline Range & $12-121$ & $6-121$ & 13-111 \\
\hline
\end{tabular}

PN, partial nephrectomy; RN, radical nephrectomy; CCPRCC, clear cell papillary renal cell carcinoma; CCRCC, clear cell renal cell carcinoma; PRCC, papillary renal cell carcinoma; SD, standard deviation.

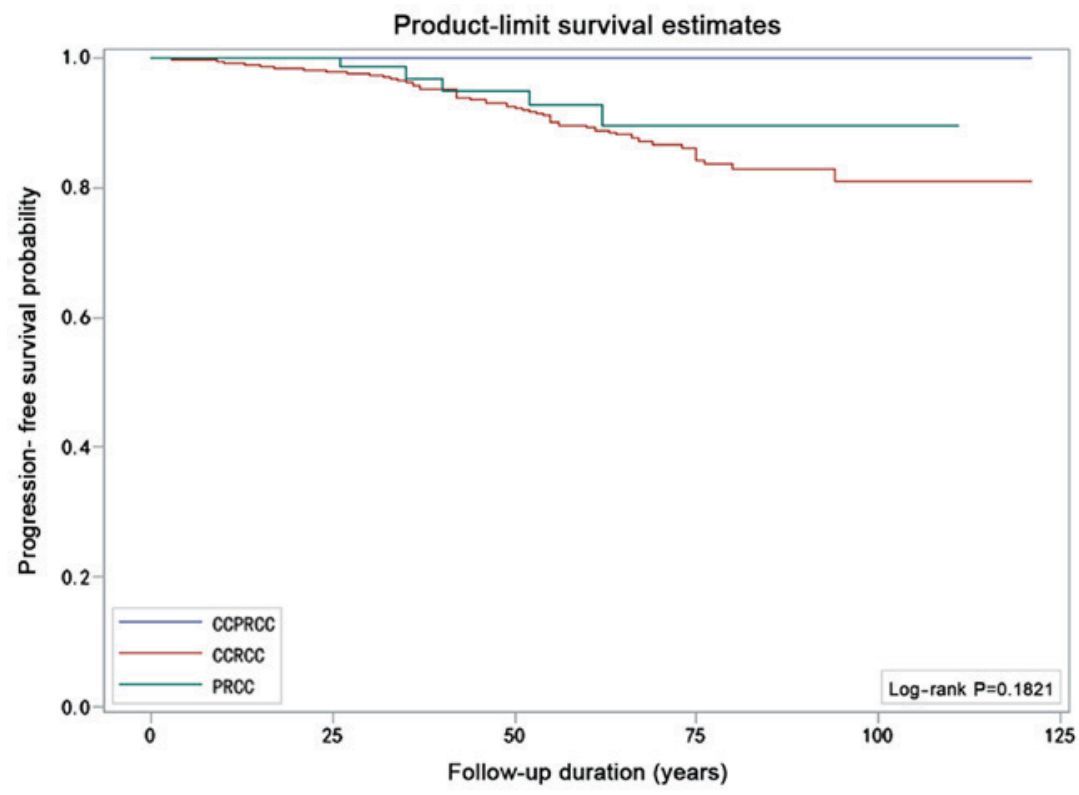

Figure 9. Kaplan-Meier survival curve estimates of the 10-year progression-free survival for all patients according to the RCC subtypes. RCC, renal cell carcinoma.

proportion. Similar results were noted in the univariate and multivariate analyses for CSS (Table VI).

\section{Discussion}

Accumulated data have demonstrated that CCPRCC is a distinct entity of renal epithelial neoplasm (7). In this study, we provided a clinical view to understand this tumor. The frequency of CCPRCC was $1.7 \%$ among 1,519 kidney resections of RCC and the mean age of patients with CCPRCC was 53.3 years. The disease was more common in men than in women, which is consistent with previous studies $(13,15,18)$. Of the 26 CCPRCC cases, the majority were asymptomatic. Only 7 patients suffered from abdominal pain or flank pain 
Table V. Univariate and multivariate analyses of patient and tumor characteristics with regard to their prognostic impact on progression-free survival (Cox regression analysis).

\begin{tabular}{|c|c|c|c|c|}
\hline \multirow[b]{2}{*}{ Variables } & \multicolumn{2}{|c|}{ Univariate analysis } & \multicolumn{2}{|c|}{ Multivariate analysis } \\
\hline & HR $(95 \%$ CI $)$ & P-value & $\mathrm{HR}(95 \% \mathrm{CI})$ & P-value \\
\hline Age (year) & & 0.58 & & 0.87 \\
\hline$\leq 60$ & 1.00 (reference) & & 1.00 (reference) & \\
\hline$>60$ & $0.86(0.52,1.44)$ & & $1.04(0.62,1.75)$ & \\
\hline Sex & & 0.82 & & 0.95 \\
\hline Female & 1.00 (reference) & & 1.00 (reference) & \\
\hline Male & $1.06(0.63,1.81)$ & & $1.02(0.60,1.73)$ & \\
\hline T stage & & $<0.0001$ & & $<0.0001$ \\
\hline T1a & 1.00 (reference) & & 1.00 (reference) & \\
\hline $\mathrm{T} 1 \mathrm{~b}$ & $6.16(3.29,11.54)$ & & $6.22(2.91,13.30)$ & \\
\hline Nuclear grade & & 0.01 & & 0.10 \\
\hline 1 & 1.00 (reference) & & 1.00 (reference) & \\
\hline 2 & $3.29(1.32,8.19)$ & & $2.16(0.86,5.47)$ & \\
\hline Operative type & & 0.02 & & 0.59 \\
\hline $\mathrm{RN}$ & 1.00 (reference) & & 1.00 (reference) & \\
\hline $\mathrm{PN}$ & $2.84(1.22,6.59)$ & & $0.76(0.27,2.08)$ & \\
\hline RCC subtype & & NA & & NA \\
\hline CCPRCC & 1.00 (reference) & & 1.00 (reference) & \\
\hline CCRCC & NA & 0.984 & NA & 0.986 \\
\hline PRCC & NA & 0.985 & NA & 0.986 \\
\hline
\end{tabular}

CI, confidence interval; HR, hazard ratio; PN, partial nephrectomy; RN, radical nephrectomy; RCC, renal cell carcinoma. NA, not available; CCPRCC, clear cell papillary renal cell carcinoma; CCRCC, clear cell renal cell carcinoma; PRCC, papillary renal cell carcinoma.

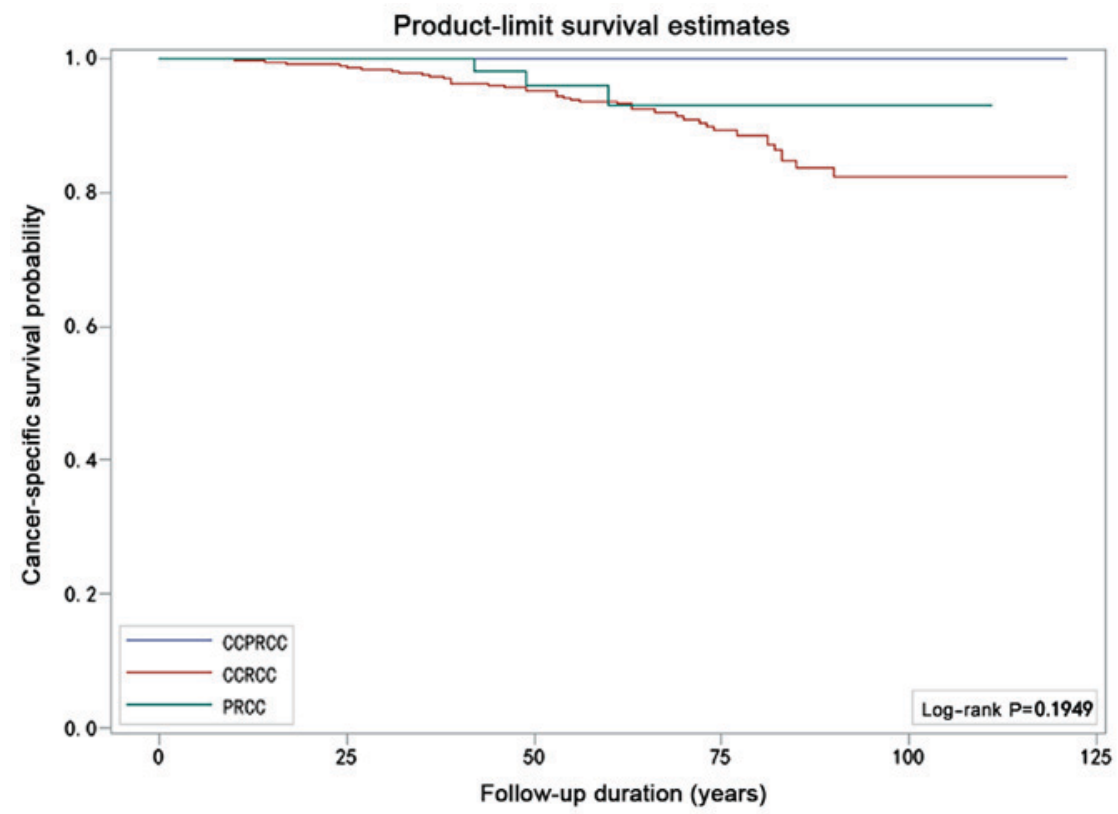

Figure 10. Kaplan-Meier survival curve estimates of the 10-year cancer-specific survival for all patients according to the RCC subtypes. RCC, renal cell carcinoma.

and 1 patient from hematuria, which reveals that patients with CCPRCC have no typical clinical symptoms. We also observed whether these patients were complicated with other kidney diseases. Multilocular renal cyst (MRC), the most common kidney disease, occurred in 4 patients, although CCPRCC was initially thought to have association with ESRD $(1,11)$. In our 
Table VI. Univariate and multivariate analyses of patient and tumor characteristics with regard to their prognostic impact on cancer-specific survival (Cox regression analysis).

\begin{tabular}{|c|c|c|c|c|}
\hline \multirow[b]{2}{*}{ Variables } & \multicolumn{2}{|c|}{ Univariate analysis } & \multicolumn{2}{|c|}{ Multivariate analysis } \\
\hline & HR (95\% CI) & P-value & HR $(95 \%$ CI $)$ & P-value \\
\hline Age (year) & & 0.62 & & 0.87 \\
\hline$\leq 60$ & 1.00 (reference) & & 1.00 (reference) & \\
\hline$>60$ & $0.86(0.48,1.55)$ & & $1.05(0.58,1.90)$ & \\
\hline Sex & & 0.53 & & 0.72 \\
\hline Female & 1.00 (reference) & & 1.00 (reference) & \\
\hline Male & $1.18(0.63,2.21)$ & & $1.12(0.60,2.10)$ & \\
\hline T stage & & $<0.0001$ & & $<0.0001$ \\
\hline T1a & 1.00 (reference) & & 1.00 (reference) & \\
\hline $\mathrm{T} 1 \mathrm{~b}$ & $8.38(3.76,18.67)$ & & $9.15(3.39,24.67)$ & \\
\hline Nuclear grade & & 0.02 & & 0.11 \\
\hline 1 & 1.00 (reference) & & 1.00 (reference) & \\
\hline 2 & 4.2 & & $2.61(0.80,8.54)$ & \\
\hline Operative type & & 0.03 & & 0.45 \\
\hline RN & 1.00 (reference) & & 1.00 (reference) & \\
\hline PN & $0.32(0.12,0.89)$ & & $0.60(0.17,2.12)$ & \\
\hline RCC subtype & & NA & & NA \\
\hline CCPRCC & 1.00 (reference) & & 1.00 (reference) & \\
\hline CCRCC & NA & 0.986 & NA & 0.988 \\
\hline PRCC & NA & 0.987 & NA & 0.988 \\
\hline
\end{tabular}

CI, confidence interval; HR, hazard ratio; PN, partial nephrectomy; RN, radical nephrectomy; RCC, renal cell carcinoma; CCPRCC, clear cell papillary renal cell carcinoma; CCRCC, clear cell renal cell carcinoma; PRCC, papillary renal cell carcinoma.

study, ESRD occurred with CCPRCC in only 1 case. In addition, there was 1 patients with bilateral renal tumors (the right side was CCPRCC and the left side was CCRCC), which is rare in the sporadic setting.

The patient's height, weight, past medical history and smoking history were recorded. Through analyzing the results, we find 17 patients $(65.4 \%)$ having body mass index (BMI) greater than $23.9 \mathrm{~kg} / \mathrm{m}^{2}, 11$ patients $(42.3 \%)$ having hypertension occurred in, and 6 patients $(23.1 \%)$ being current smokers or former smokers. Chow et al examined the health records of 363992 Swedish men who underwent at least one physical examination from 1971 to 1992, and they found that increasing blood pressure levels, obesity and cigarette smoking were independent risk factors of kidney cancer (29). This conclusion was further confirmed by Sanfilippo et al (30), through observational studies of 156774 participants over 10.8 years. The risk rose with increasing blood pressures and BMI. Furthermore, we explored the biologic mechanisms underlying these risk factors. Obesity and hypertension are associated with increased glomerular filtration rate and renal plasma flow $(30,31)$. This may render kidneys more susceptible to damage and increase in the oxygen demands of tubular cells, which in turn provokes an imbalance between oxygen delivery and oxygen demand (32). Meanwhile, obesity, hypertension and cigarette smoke are associated with oxidative stress and lipid peroxidation, which may cause an increase in oxygen consumption as well $(30,32,33)$. In addition, the combustion of tobacco produces carbon monoxide, which can be combined with hemoglobin to form carboxyhemoglobin. Finally, chronic hypoxia in the kidney potentiates the upregulation of hypoxia-inducible factors (HIFs) and CA IX, which triggers the development of ESRD or renal carcinogenesis (29-34). Coincidentally, previous studies have documented that most of CCRCC have VHL gene mutations, which can also lead to overexpression of HIF pathway associated proteins, whereas CCPRCC lack these characteristic chromosomal abnormalities $(2,18,21)$. The strong expression of HIF-1 $\alpha$ and CA IX in all tumors, however, provide supporting evidence that CCPRCC activate the HIF pathway independent of VHL gene mutation $(2,3,9,18,35)$. Thus we reasonably speculate that hypertension, obesity and smoking are the main causes of CCPRCC. The results of laboratory tests were also analyzed, but they were non-specific except for high serum uric acid in 6 patients and mild abnormal glutamic-pyruvic transaminase in 2 patients. Further research is required to find out whether there is a relationship between diet and CCPRCC.

CCPRCC often presents as small masses with similar morphological characteristics in both CCRCC and PRCC. However, there are also many different histological and immunohistochemical profiles among them. The CCPRCC has a combination of tubular, papillary, cystic and occasionally solid structures. The papillae in CCPRCC are short and aborted, which differs from PRCC, which has longer papillae and often marked by foamy histiocytes. Meanwhile, CCRCC 
rarely have papillary components, although the tumor cells of CCPRCC and CCRCC all exhibit clear cytoplasm. In addition, the Fuhrman nuclear grade of CCPRCC is low (1 or 2) and most of the nuclei are characteristically situated away from the basement membrane in a linear fashion. At least 25 kinds of antibodies are used for immunohistochemical labeling of CCPRCC (22), but it is generally accepted that the most important makers are CK7, AMACR, CD10 and CA IX $(9,18,35,36)$. It is helpful to identify CCPRCC by using these 4 kinds of antibodies if there are too many overlapping features among the 3 subtypes of RCC. CCPRCC typically is positive for CK7 and CA IX (sometimes 'cup-like' pattern), negative for AMACR and CD10 (sometimes focally positive). CCRCC in contrast, usually exhibits positive for CD10 and CA IX ('box-like' pattern), while negative for CK7 and AMACR. For PRCC, the tumor cells express strong positive immunostaining for CK7, CD10 and AMACR, but negative for CA IX. Furthermore, to our knowledge, we are the first to report the expression of Ki67 immunostaining in CCPRCC. Ki67 is a kind of nuclear-associated antigen present in the G1, S, G2 and M-phase of all cycling human cells (37). Many studies have indicated that Ki67 is a prognostic marker in several neoplasms, including kidney cancer (37,38). In this study, the Ki67 LI is significantly lower than that in CCRCC $(\mathrm{P}<0.001)$ or that in PRCC $(\mathrm{P}<0.001)$. This result is consistent with the low-grade nuclei of CCPRCC, which indicates that patients with CCPRCC may have a better prognosis.

Imaging characteristics of CCRCC and PRCC by computed tomography scan have been described by several studies. The typical enhancement pattern of CCRCC is heterogeneous. Their attenuation values markedly increase in the CMP, approaching levels in the adjacent renal cortex. Then they rapidly decrease in the NP and EP $(39,40)$. In contrast, the majority of PRCC cases are homogenous and do not enhance markedly because of hypo-vascular $(40,41)$. However, no prior studies have described the imaging of CCPRCC except Gill et al, who briefly mentioned 6 cases (15). We wonder whether there are some imaging features to identify CCPRCC from other renal tumor subtypes. Based on the results, we draw the following four conclusions. Firstly, most CCPRCC tumors were smaller than $4 \mathrm{~cm}$, which indicated a low stage (pTla) according to the 2010 TNM staging system. Secondly, the contours of CCPRCC tumors were all smooth, and no calcification was observed in these tumors. Thirdly, CCPRCC tumors often showed heterogeneity with intravenous contrast because of the mixed organization structure. The fourth and most important thing is that the multiphasic attenuation curve for CCPRCC was like that for CCRCC. This might be related to the activation of the HIF pathway in both CCPRCC and CCRCC, which led to hyper vascularity in tumors. Nevertheless, not all CCPRCC cases had such image features. We also observed 2 cases, in which the enhancement magnitudes were relatively low and the enhancement peaked in the NP, resembling typical of PRCC tumors. By reviewing the 2 pathological sections, we found that they both demonstrated significant cysts formation, covering $80-90 \%$ of the tumor. The rest area of the tumors contained delicate papillae and the stroma only had a small number of capillaries. We suspect that this was due to insufficient tumor blood supply caused by the cyst compression. But it still needs further verification.
The development and widespread use of radiologic imaging techniques have increased the detection rate of incidental small RCCs (42). Meanwhile, the incidence of CCPRCC increased significantly in the RCCs with early stage and low nuclear grade. Thus, predicting the biological potential of CCPRCC is extremely helpful for choosing treatment. The results of our study showed that neither cancer-specific death nor tumor recurrence was observed at a median follow-up period of 50 months (range 12-121 months), whether in partial nephrectomy or radical nephrectomy cases. Other CCPRCC studies have similarly shown excellent oncologic outcomes $(7,10,13,15)$. The favorable prognosis of CCPRCC suggested that it was consistent with the low expression of Ki67. Furthermore, the multivariate analysis showed that only tumor size was an independent prognostic factor whether it was in PFS or CSS, and the survival time of patients had nothing to do with the operation methods. Thus in diagnosis and treatment of RCC, preoperative CT examination is necessary. For early stage tumors, especially those smaller than $4 \mathrm{~cm}$ and like the radiological features of CCPRCC, we recommend renal tumor biopsy before surgery in order to verify the diagnosis. Partial nephrectomy is an appropriate surgical procedure for CCPRCC. In patients of old age, ESRD, or with some comorbidities (such as cardiac/pulmonary insufficiency), however, there is a high risk in surgery. Whether these patients need close surveillance or radiofrequency ablation requires further consideration.

Several limitations of our study should be considered. Firstly, not all the 26 patients with CCPRCC underwent CT because of the retrospective study. Only 14 patients were evaluated for multiphasic enhancement, including 10 patients underwent four-phase scanning. But this is the maximum number of samples that have ever been reported and we believe that these cases are enough for analyzing the image features of CCPRCC. Secondly, this is a co-conducted study and the equipment models are not the same in both hospitals. However, most of renal masses were evaluated with a standardized protocol. Furthermore, to reduce errors in measurement, the patients with CCRCC or PRCC were selected according to the proportion of CCPRCC in the two hospitals. We also believe that a robust identification method should be as widely applicable as possible. Thirdly, the CT images of patients with ESRD are not evaluated because samples are rare. Whether their results are consistent with that of the patients with normal renal function remains to be further studied. Fourthly, though we have data on magnetic resonance and contrast-enhanced ultrasound in patients with CCPRCC, a comparative study cannot be carried out, because the data is little. We will pay more attention to this part of the study. Finally, although the 10 year PFS and CSS rates of CCPRCC were lower than those of CCRCC and PRCC in the early stage of RCC with low nuclear grade, the differences were not statistically significant. This result may be associated with small sample size and lack of long-term follow-up time in our study. In addition, there are no studies of metastases or recurrences of CCPRCC published to date $(1-3,7-10,26)$. Therefore, we can not deny that CCPRCC has a better prognosis than CCRCC or PRCC. In view of its lower incidence, maybe a meta-analysis is necessary to answer this question.

In conclusion, the present study contributes to further understanding of this unique renal tumor. We suggest that 
urologists and oncologists should be aware of the image features of CCPRCC and its favorable prognosis, apart from knowing its distinct morphological features and diagnosing it with immunohistochemistry. For early stage RCC cases, especially for those having a smaller than $4 \mathrm{~cm}$ size, smooth contour and a high degree of enhancement in CMP, the possibility of CCPRCC should be considered. If the diagnosis is made by biopsy before operation, radical nephrectomy requires careful consideration. Larger cohorts of patients will provide more information for pathogenesis study, diagnosis and treatment of this tumor type.

\section{Acknowledgements}

Not applicable.

\section{Funding}

This study was supported by the National Natural Science Foundation of China (grants nos. 81570676, 81672531 and 81502089), the Priority Academic Program Development of Jiangsu Higher Education Institutions ' 333 high level talents project' in Jiangsu province (grant no. BRA2015469), the six talents peak project in Jiangsu Province (grants nos. WSN-011 and WSN-056) and the Natural Science Foundation of Jiangsu Province (grant no. BK20151024).

\section{Availability of data and materials}

The datasets used and/or analyzed during the current study are available from the corresponding author on reasonable request.

\section{Authors' contributions}

YQW, MG and CQ conceived and designed the experiments. YD, ZJW, CHH, HXL, XL, PFW and GCL collaborated in assessing the patient data. YD, JW, ZJW, CHH, HXL, XL, PFW and GCL performed analysis and interpretation of the data. YQW wrote the paper. MG and CQ checked and edited the paper. All authors read and approved the final version of the manuscript.

\section{Ethics approval and consent to participate}

This study was approved by the Ethics Committee of the First Affiliated Hospital of Nanjing Medical University (approval no. 2016-SRFA-011) and the Ethics Committee of the Affiliated Xuzhou Hospital of Medical College of Southeast University (approval no. XZXY-LJ-20160111-008). Written informed consent was obtained from all patients and/or their guardians.

\section{Consent for publication}

Informed consent for the publication of any associated data and accompanying images was obtained from all individuals.

\section{Competing interests}

The authors declare that they have no competing interests.

\section{References}

1. Tickoo SK, dePeralta-Venturina MN, Harik LR, Worcester HD, Salama ME, Young AN, Moch H and Amin MB: Spectrum of epithelial neoplasms in end-stage renal disease: An experience from 66 tumor-bearing kidneys with emphasis on histologic patterns distinct from those in sporadic adult renal neoplasia. Am J Surg Pathol 30: 141-153, 2006.

2. Gobbo S, Eble JN, Grignon DJ, Martignoni G, Maclennan GT, Shah RB, Zhang S, Brunelli M and Cheng L: Clear cell papillary renal cell carcinoma: A distinct histopathologic and molecular genetic entity. Am J Surg Pathol 32: 1239-1245, 2008.

3. Aydin H, Chen L, Cheng L, Vaziri S, He H, Ganapathi R, Delahunt B, Maqi-Galluzzi C and Zhou M: Clear cell tubulopapillary renal cell carcinoma: A study of 36 distinctive low-grade epithelial tumors of the kidney. Am J Surg Pathol 34: 1608-1621, 2010.

4. Adam J, Couturier J, Molinié V, Vieillefond A and Sibony M: Clear-cell papillary renal cell carcinoma: 24 cases of a distinct low-grade renal tumour and a comparative genomic hybridization array study of seven cases. Histopathology 58: 1064-1071, 2011.

5. Srigley JR, Delahunt B, Eble JN, Egevad L, Epstein JI, Grignon D, Hes O, Moch H, Montironi R, Tickoo SK, et al: The International Society of Urological Pathology (ISUP) Vancouver Classification of renal neoplasia. Am J Surg Pathol 37: 1469-1489, 2013.

6. Moch H, Cubilla AL, Humphrey PA, Reuter VE and Ulbright TM: The 2016 WHO Classification of Tumours of the urinary system and male genital organs-part A: Renal, penile, and testicular tumours. Eur Urol 70: 93-105, 2016.

7. Zhou H, Zheng S, Truong LD, Ro JY, Ayala AG and Shen SS: Clear cell papillary renal cell carcinoma is the fourth most common histologic type of renal cell carcinoma in 290 consecutive nephrectomies for renal cell carcinoma. Hum Pathol 45: 59-64, 2014.

8. Park JH, Lee C, Suh JH and Moon KC: Clear cell papillary renal cell carcinoma: A report of 15 cases including three cases of concurrent other-type renal cell carcinomas. Korean J Pathol 46: 541-547, 2012.

9. Williamson SR, Eble JN, Cheng L and Grignon DJ: Clear cell papillary renal cell carcinoma: Differential diagnosis and extended immunohistochemical profile. Mod Pathol 26: 697-708, 2013.

10. Alexiev BA and Drachenberg CB: Clear cell papillary renal cell carcinoma: Incidence, morphological features, immunohistochemical profile, and biologic behavior: A single institution. Pathol Res Pract 210: 234-241, 2014.

11. Bhatnagar R and Alexiev BA: Renal-cell carcinomas in end-stage kidneys: A clinicopathological study with emphasis on clear-cell papillary renal-cell carcinoma and acquired cystic kidney disease-associated carcinoma. Int J Surg Pathol 20: 19-28, 2012.

12. Aron M, Chang E, Herrera L, Hes O, Hirsch MS, Comperat E, Camparo P, Rao P, Picken M, Michal M, et al: Clear cell-papillary renal cell carcinoma of the kidney not associated with end-stage renal disease: Clinicopathologic correlation with expanded immunophenotypic and molecular characterization of a large cohort with emphasis on relationship with renal angiomyoadenomatous tumor. Am J Surg Pathol 39: 873-888, 2015.

13. Leroy X, Camparo P, Gnemmi V, Aubert S, Flamand V, Roupret M, Fantoni JC and Compérat E: Clear cell papillary renal cell carcinoma is an indolent and low-grade neoplasm with overexpression of cyclin-D1. Histopathology 64: 1032-1036, 2014.

14. Rao P, Monzon F, Jonasch E, Matin SF and Tamboli P: Clear cell papillary renal cell carcinoma in patients with von Hippel-Lindau syndrome-clinicopathological features and comparative genomic analysis of 3 cases. Hum Pathol 45: 1966-1972, 2014.

15. Gill S, Kauffman EC, Kandel S, George S, Schwaab T and $\mathrm{Xu} \mathrm{B}$ : Incidence of clear cell papillary renal cell carcinoma in low-grade renal cell carcinoma cases: A 12-year retrospective clinicopathologic study from a single cancer center. Int J Surg Pathol 24: 207-212, 2016.

16. Sahni VA, Hirsch MS and Silverman SG: Renal angiomyoadenomatous tumour: Imaging features. Can Urol Assoc J 6: E140-E143, 2012.

17. Shao T, Yousef P, Shipilova I, Saleeb R, Lee JY and Krizova A: Clear cell papillary renal cell carcinoma as part of histologically discordant multifocal renal cell carcinoma: A case report and review of literature. Pathol Res Pract 212: 229-233, 2016.

18. Shi SS, Shen Q, Xia QY, Tu P, Shi QL, Zhou XJ and Rao Q: Clear cell papillary renal cell carcinoma: A clinicopathological study emphasizing ultrastructural features and cytogenetic heterogeneity. Int J Clin Exp Pathol 6: 2936-2942, 2013. 
19. Deml KF, Schildhaus HU, Compérat E, von Teichman A, Storz M, Schraml P, Bonventre JV, Fend F, Fleige B, Nerlich A, et al: Clear cell papillary renal cell carcinoma and renal angiomyoadenomatous tumor: Two variants of a morphologic, immunohistochemical, and genetic distinct entity of renal cell carcinoma. Am J Surg Pathol 39: 889-901, 2015.

20. Yan WX, Cao WR, Zhao J, Zhang W, Wang XL, Yuan Q and Dang SQ: Clear cell papillary renal cell carcinoma: A clinicopathologic analysis of 6 cases. Int J Clin Exp Pathol 8: 4595-4599, 2015.

21. Lawrie CH, Larrea E, Larrinaga G, Goicoechea I, Arestin M, Fernandez-Mercado M, Hes O, Cáceres F, Manterola L and López JI: Targeted next-generation sequencing and non-coding RNA expression analysis of clear cell papillary renal cell carcinoma suggests distinct pathological mechanisms from other renal tumour subtypes. J Pathol 232: 32-42, 2014.

22. Diolombi ML, Cheng L, Argani P and Epstein JI: Do clear cell papillary renal cell carcinomas have malignant potential? Am J Surg Pathol 39: 1621-1634, 2015.

23. Alexiev BA and Zou YS: Clear cell papillary renal cell carcinoma: A chromosomal microarray analysis of two cases using a novel Molecular Inversion Probe (MIP) technology. Pathol Res Pract 210: 1049-1053, 2014

24. Fisher KE, Yin-Goen Q, Alexis D, Sirintrapun JS, Harrison W, Benjamin Isett R, Rossi MR, Moreno CS, Young AN and Osunkoya AO: Gene expression profiling of clear cell papillary renal cell carcinoma: Comparison with clear cell renal cell carcinoma and papillary renal cell carcinoma. Mod Pathol 27: 222-230, 2014

25. Munari E, Marchionni L, Chitre A, Hayashi M, Marrtignoni G, Brunelli M, Gobbo S, Arqani P, Allaf M, Hoque MO and Netto GJ: Clear cell papillary renal cell carcinoma: micro-RNA expression profiling and comparison with clear cell renal cell carcinoma and papillary renal cell carcinoma. Hum Pathol 45: 1130-1138, 2014.

26. Alexiev BA, Thomas $C$ and Zou YS. Clear cell papillary renal cell carcinoma with angiomyomatous stroma: A histological, immunohistochemical, and fluorescence in situ hybridization study. Virchows Arch 464: 709-716, 2014.

27. DhakalHP,Mckenney JK, Khor LY, Reynolds JP,Magi-Galluzzi C and Przybycin CG: Renal neoplasms with overlapping features of clear cell renal cell carcinoma and clear cell papillary renal cell carcinoma: A clinicopathologic study of 37 cases from a single institution. Am J Surg Pathol 40: 141-154, 2016.

28. Delahunt B, Bethwaite PB, Thornton A and Ribas JL: Proliferation of renal cell carcinoma assessed by fixation-resistant polyclonal Ki-67 antibody labeling. Correlation with clinical outcome. Cancer 75: 2714-2719, 1995.

29. Chow WH, Gridley G, Fraumeni JF Jr and Järvholm B: Obesity, hypertension, and the risk of kidney cancer in men. New Engl J Med 343: 1305-1311, 2000.

30. Sanfilippo KM, Mctigue KM, Fidler CJ, Neaton JD, Chang Y, Fried LF, Liu S and Kuller LH: Hypertension and obesity and the risk of kidney cancer in 2 large cohorts of US men and women. Hypertension 63: 934-941, 2014.
31. Khandekar MJ, Cohen P and Spiegelman BM: Molecular mechanisms of cancer development in obesity. Nat Rev Cancer 11: 886-895, 2011

32. Shoji K, Tanaka T and Nangaku M: Role of hypoxia in progressive chronic kidney disease and implications for therapy. Curr Opin Nephrol Hypertens 23: 161-168, 2014.

33. Kabaria R, Klaassen $\mathrm{Z}$ and Terris MK: Renal cell carcinoma: Links and risks. Int J Nephrol Renovasc Dis 9: 45-52, 2016.

34. Weikert S, Boeing H,Pischon T, WeikertC, Olsen A, Tjonneland A, Overvad K, Becker N, Linseisen J, Trichopoulou A, et al: Blood pressure and risk of renal cell carcinoma in the European prospective investigation into cancer and nutrition. Am J Epidemiol 167: 438-446, 2008.

35. Kuroda N, Ohe C,Kawakami F, Mikami S, Furuya M, Matsuura K, Moriyama M, Nagashima Y, Zhou M, Petersson F, et al: Clear cell papillary renal cell carcinoma: A review. Int J Clin Exp Pathol 7: 7312-7318, 2014.

36. Pramick M,Ziober A and Bing Z: Useful immunohistochemical panel for differentiating clear cell papillary renal cell carcinoma from its mimics. Ann Diagn Pathol 17: 437-440, 2013.

37. Gayed BA, Youssef RF, Bagrodia A, Darwish OM, Kapur P, Sagalowsky A, Lotan Y and Margulis V: Ki67 is an independent predictor of oncological outcomes in patients with localized clear-cell renal cell carcinoma. BJU Int 113: 668-673, 2014.

38. Gerdes J: Ki-67 and other proliferation markers useful for immunohistological diagnostic and prognostic evaluations in human malignancies. Semin Cancer Biol 1: 199-206, 1990.

39. Young JR, Margolis D, Sauk S, Pantuck AJ, Sayre J and Raman SS: Clear cell renal cell carcinoma: Discrimination from other renal cell carcinoma subtypes and oncocytoma at multiphasic multidetector CT. Radiology 267: 444-453, 2013.

40. Zhang J, Lefkowitz RA, Ishill NM, Wang L, Moskowitz CS, Russo P, Eisenberg H and Hricak H: Solid renal cortical tumors: Differentiation with CT. Radiology 244: 494-504, 2007.

41. Tsuda K, Kinouchi T, Tanikawa G, Yasuhara Y, Yanagawa M, Kakimoto K, Ono Y, Meguro N, Maeda O, Arisawa J and Usami M: Imaging characteristics of papillary renal cell carcinoma by computed tomography scan and magnetic resonance imaging. Int J Urol 12: 795-800, 2005.

42. Kim JM, Song PH, Kim HT and Park TC: The prognostic factors for patients with pT1a renal cell carcinoma. Korean J Urol 51: 233-238, 2010.

This work is licensed under a Creative Commons Attribution-NonCommercial-NoDerivatives 4.0 International (CC BY-NC-ND 4.0) License. 